\title{
CARACTERIZAÇÃO DA RESISTÊNCIA AOS ANTIMICROBIANOS DE Staphylococcus spp. ISOLADOS DE MASTITE BOVINA
}

\author{
CHARACTERISTICS OF ANTIMICROBIAL RESISTENCE OF Staphylococcus spp. \\ ISOLATED FROM BOVINE MASTITIS
}

\author{
J. P. DOS SANTOS ${ }^{1 *}$, S. C. BRASÃO ${ }^{2}$, A. FERREIRA-JÚNIOR ${ }^{1}$, C. C. LOCCE $^{3}$, E. R. BITTAR ${ }^{1}$, \\ J. F. F. BITTAR ${ }^{1}$
}

\section{RESUMO}

A mastite pode ser causada por muitos agentes infecciosos diferentes, e é a doença infecciosa mais comumente encontrada em bovinos leiteiros de criação intensiva. Os objetivos deste trabalho foram: (i) isolar bactérias do gênero Staphylococcus do leite de vacas com mastite e (ii) identificar os antimicrobianos para os quais elas apresentam maior sensibilidade e resistência in vitro. Foi realizado um estudo retrospectivo com 122 Staphylococcus spp. isolados de leites de vacas com mastite enviados ao Hospital Veterinário de Uberaba (HVU), no período de janeiro de 2010 a junho de 2014. As bactérias foram identificadas de acordo com suas características morfológicas e bioquímicas. O teste de sensibilidade aos antimicrobianos foi realizado pelo método Kirby-Bauer de difusão em disco. Foram testados os seguintes antibióticos: ampicilina; amoxicilina/ácido clavulâmico; cefalexina; ceftiofur; ciprofloxacina; eritromicina; enrofloxacina; gentamicina; oxacilina; penicilina; sulfa/trimetoprim ; tetraciclina e tilmicosin. Destes isolados, $59 \%$ (72/122) eram de Staphylococcus coagulase-positivo (SCP) e 41\% (50/122) de Staphylococcus coagulase-negativo (SCN). Os melhores resultados observados foram para Amoxicilina/ácido clavulânico, Ceftiofur, Ciprofloxacina, Florfenicol e Gentamicina, e sugerem que estas bases podem ser opções terapêuticas para mastite estafilocócica da região de Uberaba, Minas Gerais. Para Penicilina os SCP e SCN apresentaram resistência de 78,1\% e 71,3\%, respectivamente. Também para estes dois grupos de bactérias verificou-se resistência de 61,9 e 60\%, respectivamente, para Ampicilina. A resistência a estes fármacos foi a observação mais frequente nos dois grupos analisados. Nos rebanhos leiteiros do município de Uberaba, Minas Gerais, os estafilococos penicilina resistente estão presentes. O uso indiscriminado de antibióticos e a falta de execuções de testes de cultura e antibiograma para direcionar os tratamentos pode estar contribuindo para a resistência dos isolados, além disto, a presença destes microrganismos em produtos lácteos pode indicar risco aos consumidores, uma vez que eles podem veicular enterotoxinas estafilocócicas termoestáveis e resíduos de antimicrobianos.

PALAVRAS-CHAVE: BACTÉRIA. LEITE. RESISTÊNCIA. TRATAMENTO.

ÁREA TEMÁTICA: Doenças infecciosas

\footnotetext{
${ }^{1}$ Universidade de Uberaba (UNIUBE). Instituto de Estudos Avançados José Caetano Borges. Campus Aeroporto.

* jandra.santos@uniube.br

${ }^{2}$ Universidade Federal de Uberlândia (UFU)

${ }^{3}$ Médica Veterinária autônoma
} 